\title{
3D PRINTED JEWELLERY DESIGN PROCESS BASED ON SCULPTURE INSPIRATION
}

\author{
Karin Košak, Deja Muck (D), Marjeta Čuk (D), Tanja Nuša Kočevar \\ University of Ljubljana, Faculty of Natural Sciences and Engineering, Department of Textiles, \\ Graphic Arts and Design, Chair of Information and Graphic Arts Technology, Ljubljana, Slovenia
}

\begin{abstract}
In the article we present the educational process in which design students were guided through their design process, creating 3D printed jewellery inspired by the Forma Viva sculptures of the outdoor gallery Kostanjevica na Krki. The assignment was part of the international project Cumulus Re/Forma Viva, whose main goal was to implement digitization using 3D technology in the field of education for the preservation of cultural heritage.

The task given to the 1st year masters students of Fashion and Textile Design at the Department of Textiles, Graphic arts and Design at the University of Ljubljana was to select a wooden sculpture and transform the visual and conceptual idea into a 3D printed jewellery collection.

The curriculum of the course includes teaching the theoretical basics of 3D printing, 3D print design -fashion accessories and new production, business and marketing models as "disruptive" changes that result from this. In the practical part, students will learn the advanced design process of fashion accessory objects, including 3D technologies such as 3D modelling and 3D printing. Students are guided through a process in which selected visual and conceptual content is translated into fine jewellery that can be created using various 3D printing technologies.

In this way, students tested themselves in two new areas that allowed them to expand their design knowledge and experience in 3D modelling and jewellery design with the goal of better "arming" themselves with the latest technologies for today's competitive world.
\end{abstract}

Key words: 3D printing, jewellery design, sculpture, Forma Viva, education

\section{INTRODUCTION}

Additive manufacturing is increasingly used in the development of fashion products such as clothing, accessories and jewellery. From a design perspective, the new technology offers designers the freedom to create and manufacture things that were otherwise very difficult to produce using traditional techniques. With the new technology of 3D modelling and printing, creativity can now be explored even further (Yap et al, 2014). Master Course at the Fashion and Textile Design includes the subject Digital design 4b, which course curriculum involves teaching the advanced design process of fashion accessories objects, including 3D technologies such as 3D modelling and 3D printing. The assignment given to the students was to select the wooden sculpture from the Forma Viva outdoor gallery Kostanjevica na Krki and translate it into a 3D printed jewellery collection.

The Forma Viva presents Open Air Wood Sculpture Collection in Kostanjevica na Krki. It is the product of a biennially held International Symposia of Sculptors during which chosen artists are invited to contribute to the ever growing collection of works since 1961.

The collection comprises around 130 pieces almost exclusively fashioned out of oak wood. Most of them are gathered in a freely accessible park in front of the Kostanjevica Monastery though some can also be found in the surrounding meadows or town squares and on the banks of the river Krka (Milovanović et al, 2010). On the initial excursion to Kostanjevica, the students viewed all the sculptures and then decided on the one that appealed to them the most. Thus, each student chose one of the sculptures, analyzed it and tried to transfer the basic idea of the author as authentically as possible into usable pieces of jewellery. The jewellery industry basically still works with traditional production methods that are far too time-consuming and sometimes not efficient enough compared to the quality of the final product (Ferreira et al, 2013). 3D-printed jewellery has gained high acceptance among customers, designers and manufacturers in the fashion industry, especially because of the materials currently available that are suitable for the application. 3D printed jewellery could be made with a variety of materials, including stainless steel, bronze and even gold (Yap et al, 2014). There are many advantages of 3D printed jewellery, for example: once a designer makes a sketch of a piece of jewellery and generates a 3D model, it can be printed as a plastic prototype to verify the quality of the design, and then it can be printed in the desired metal. It is also important to note 
that 3D printing technology enables the production of very detailed objects. Software can also be used to make changes quickly and easily and to fully personalise products.

In the theoretical part, students were introduced to advanced techniques for producing tangible products and with the latest achievements of online information technologies, from social networks to support the development of the most sophisticated products possible, to websites that enable the funding of new projects. 3D printing enables a young designer to design from the student's room and also to manufacture and sell his products - jewellery - across platforms (Anderson, 2013). In such an association, it is a great new opportunity to be successful as a designer - as a small business owner.

Designers like Francis Bitonti, Iris van Herpen and Zaha Hadid show the way of avant-garde product, fashion and accessory design with new technologies. A very good example is also the company Nervous Systems, which deals with innovative business models for the design, promotion and sale of unique design and technologically advanced jewellery.

In the practical part, students applied the design part of the process to the development and implementation of jewellery prototypes on the theme of Forma Viva. This was followed by the transformation of the sculpture into a collection of functional jewellery - especially earrings, brooches, bracelets, necklaces and chokers. The jewellery was then printed on various printers at the faculty, 3D printer based on stereolithography, Form 2, 3D printers based on thermoplastic extrusion, fused deposition modeling, 3D Jozko and ZMorph 2.0 SX and 3D printer based on selective laser melting, LPM100 in the company Dentas, Maribor.

\section{DESIGN PROCESS}

\subsection{Research and analysis}

The design process began with the excursion to Forma Viva in Kostanjevica na Krki, where the students created a photographic documentation of the sculptures. Looking at the whole statue from different angles was as important as observing details and special features of statue making, so they had to take a whole series of photos to capture all views of the sculptures. Figure 1 shows two photographs of a sculpture "En rez" (A cut) by the author Primož Pugelj.
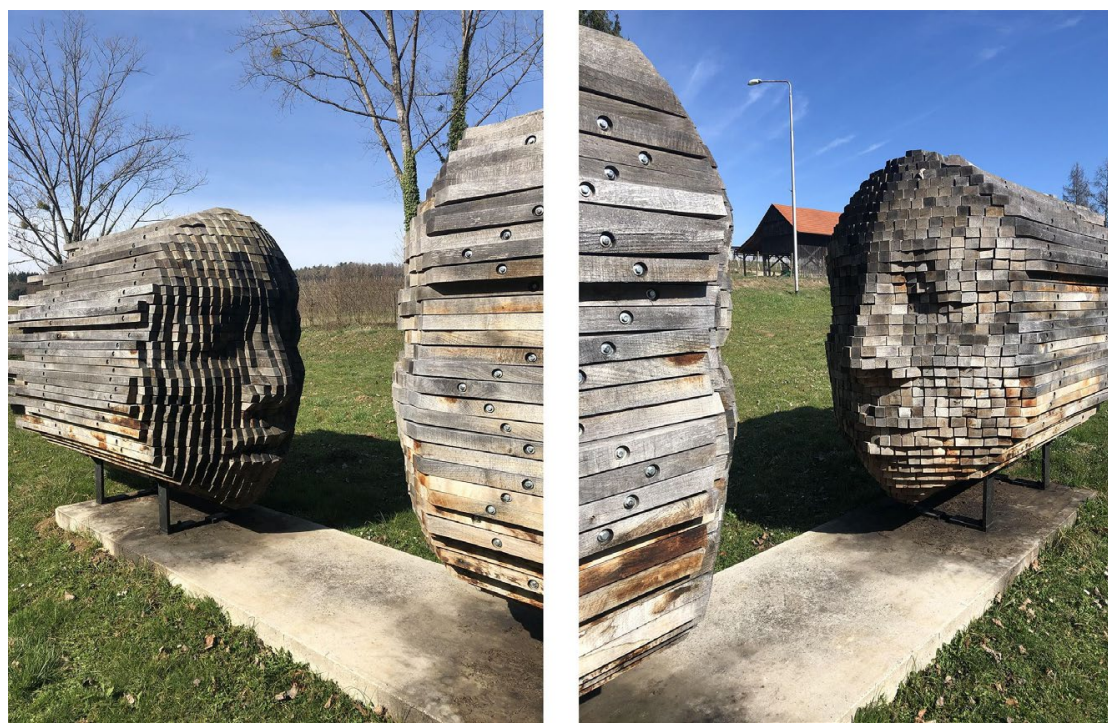

Figure 1: Photos of a sculpture "En rez" (A cut), author Primož Pugelj, photo Ajda Rep

Students thoroughly analysed chosen sculptures from a visual, conceptual and production perspective, and the investigation of possible interpretations in a jewellery collection has begun. It was important that the student really understood the intention of the author of the sculpture. It was also necessary to bring a study of contemporary jewellery up to date. Through this research, students broaden their understanding of trends in jewellery design, focusing on aesthetics, materiality and the content of the message conveyed by the design.

The process continued with the sketching of various pieces of jewellery and their rough visualisation on a body. Visualisation on the body is extremely important to correctly assess and analyse the shape and the 
proportion of a piece of jewellery according to the body silhouette. Sometimes it was also necessary to implement the ideas in paper or any other material to test the idea in 3D objects. Figure 2 and Figure 3 show the sketches in which the students thought about the type and form of the jewellery and also how it should be used or equipped to be worn.

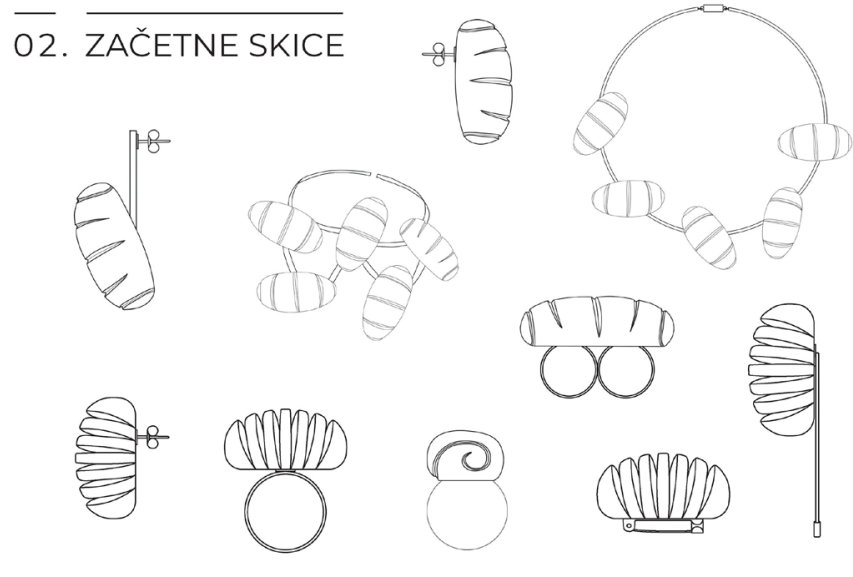

Figure 2: Initial sketches of the jewellery, author: Tina Dovjak

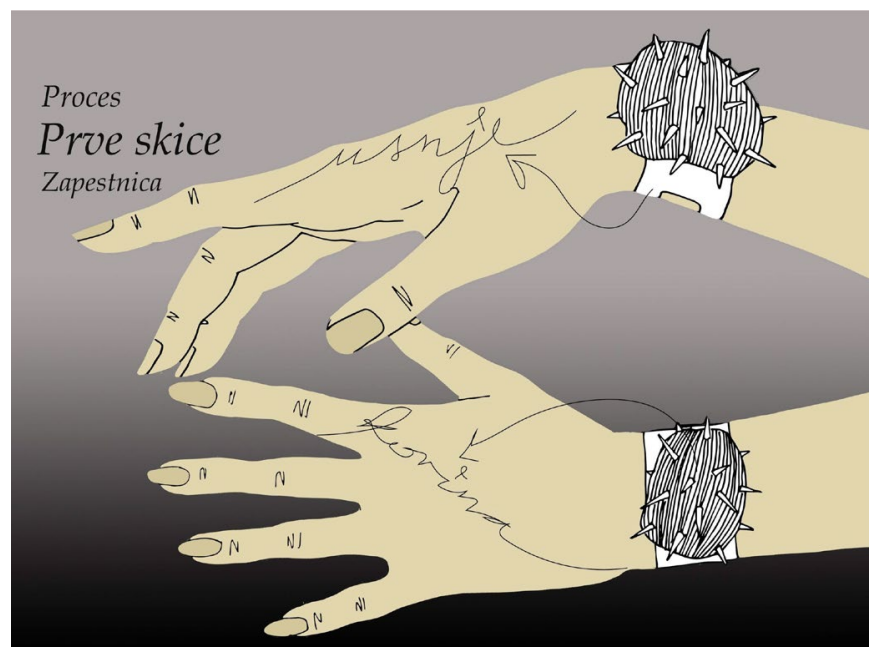

Figure 3: Visualisation of the jewellery on the body, author: Eva Jelenc

\subsection{Creation and 3D modelling}

Students were guided through a process in which selected visual and conceptual content, presented with initial sketches, was transformed into fine jewellery that can be created using various 3D printing technologies. They used a 3D programme Blender, which allows the precise modelling of very detailed objects. One student also used a 3D model originally created with photogrammetry and remodelled it and redesigned it into a piece of jewellery. The students generated various solutions that were analysed regarding concept, trends, market, technical requirements and aesthetics and the best solution was selected for 3D printing. In Figure 4 designs modelled in Blender are presented, and in Figure 5 an initial 3D model created with photogrammetry. The process of 3D modelling was sometimes very demanding, especially when designing models with additional features, as we can see in Figure 6 where some parts of the model can be moved or rotated, as is possible with the original sculpture. 


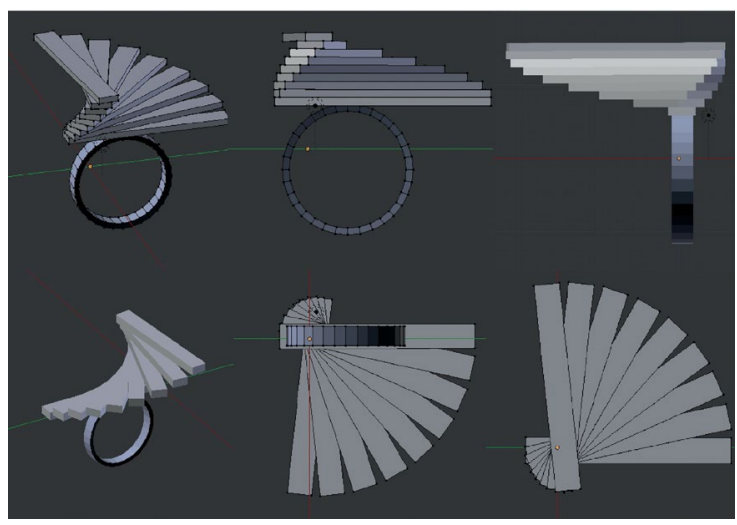

Figure 4: 3D model of the ring, author: Katrin Večerina

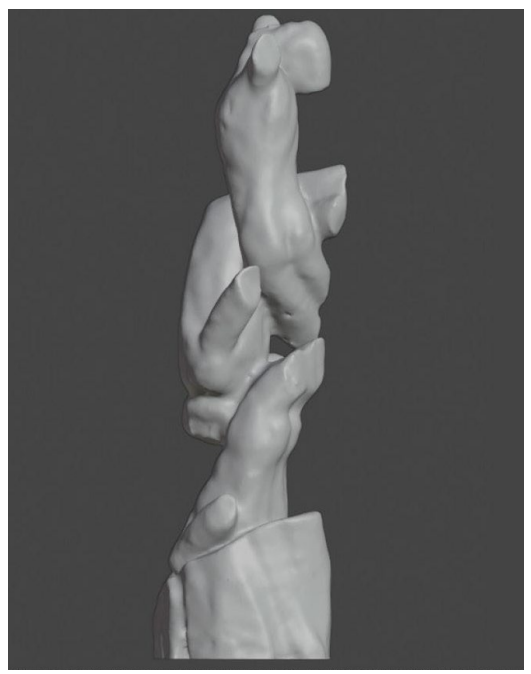

Figure 5: 3D model of the sculpture made using photogrammetry, authors: Jure Sulič, Sanja Celeste Smaragli, Ana Krklec

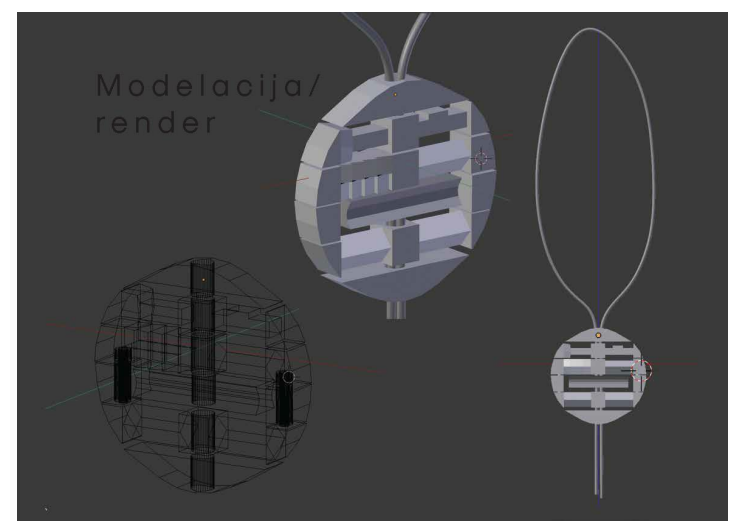

Figure 6: 3D model of the pendant with movable parts, author: Ela Vehovec

\subsection{D printing of jewellery}

When 3D models of designed jewellery were created, it was necessary to prepare them for 3D printing. The students defined the exact dimensions of the objects and checked the topology of the models. It was also important to prepare the models according to the requirements of the chosen 3D printing technology and to take into account the weight of an individual final piece of jewellery, as it should not be too heavy to wear, especially pieces printed with metal. The jewellery was printed with different 3D printing technologies. Most of the jewellery was printed with fused deposition modeling technology (FDM), using 
printer 3DJozko and multitool ZMorph $2.0 \mathrm{SX}$ printer. For pieces with very smooth surfaces the stereolithography (SLA) was used and printed with Form 2 printer. At the end some special jewellery pieces were chosen for printing with selective laser melting technology, SLM. For this reason we cooperated with company Dentas.

\section{RESULTS AND DISCUSSION}

\subsection{Fused deposition modeling, FDM}

Two different filaments based on PLA thermoplastic were used for printing with FDM technology. The first was made of coloured bronze and the second of biocomposite with wood fibers. The perimeter of both filaments was the same $1.75 \mathrm{~mm}$. The printing parameters were set by default for printing with PLA filament. Infill pattern was linear in horizontal direction at infill density $40 \%$. The layer thickness was 100 microns. In Figure 7 we see pieces of jewellery printed with bronze filament. The mentioned filament was chosen to achieve lustre, warm colour and smooth texture that enhance the appearance of printed pieces.

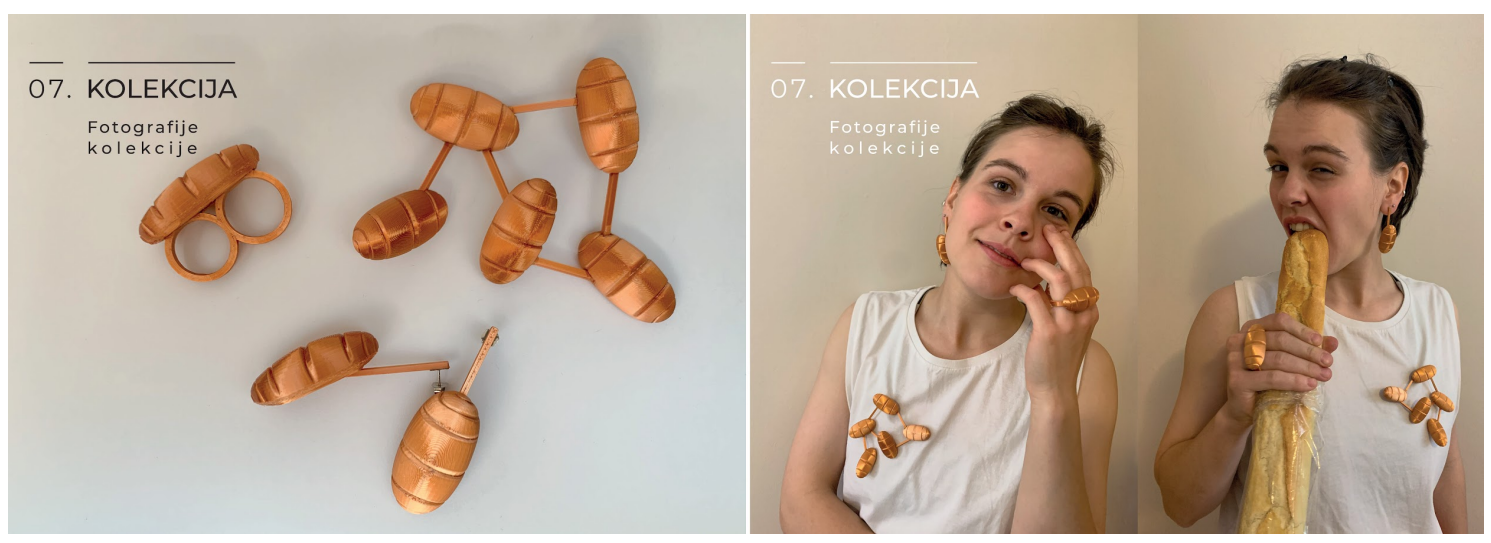

Figure 7: jewellery collection "Hlebci" (Loafs), printed with FDM technology, author Tina Dovjak, pages from presentation brochure

On Figure 8 the pendant that is printed in 6 pieces is presented. Some movable parts were printed in one piece and another were printed separately and assembled together on a string. On Figure 9, the jewellery collection is presented that is printed with the polymer that contains $40 \%$ recycled wood (PLA 2000 WOOD Bamboo). The texture is rougher and the colour is reminiscent of light wood. When printing with this polymer, the choice of the angle of the layer deposition is important to create differences in the gloss of the surface.

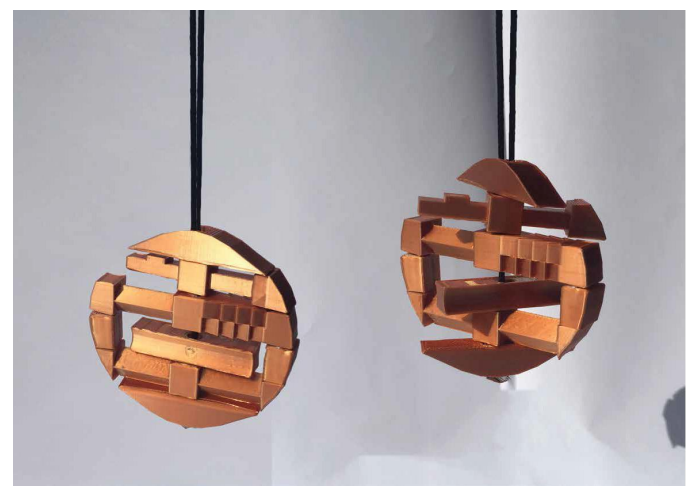

Figure 8: The pendant from the collection "Revolucija" (Revolution) printed with FDM technology, author Ela Vehovec 


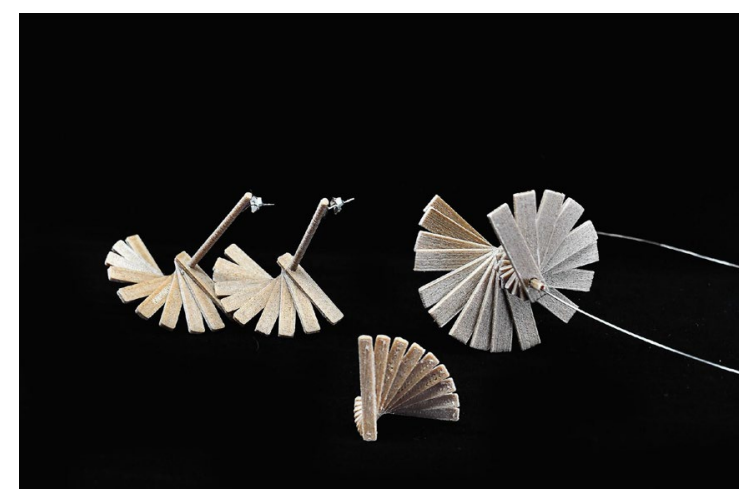

Figure 9: Jewellery collection "Spirala" (Spiral) printed with FDM technology, author Katrin Večerina, photo Maja Večerina

\subsection{Stereolithography, SLA}

Grey Pro Resin was used for printing with stereolithography printer Form 2. It is an Engineering Resin designed for high precision, moderate elongation, and low creep. These mechanical properties make Grey Pro Resin a versatile material for a wide range of applications, including concept modeling and functional prototyping. Highly resistant to deformation over time, Grey Pro Resin is especially suitable for printing parts intended for repeated use, such as jewellery (Formlabs). Printing with Form 2 printer using grey resin gives nice results. The pieces of jewellery with very smooth surfaces and visible small details. The print resolution was set to 50 microns. For better final effect post-processing was used. On Figure 10 a piece of jewellery printed with SLA technology is presented. It was printed in three pieces. After the printing process individual pieces were finished with spray painting that applied colour and shine to the product and assembled with glue what is shown on the left side of Figure 10.
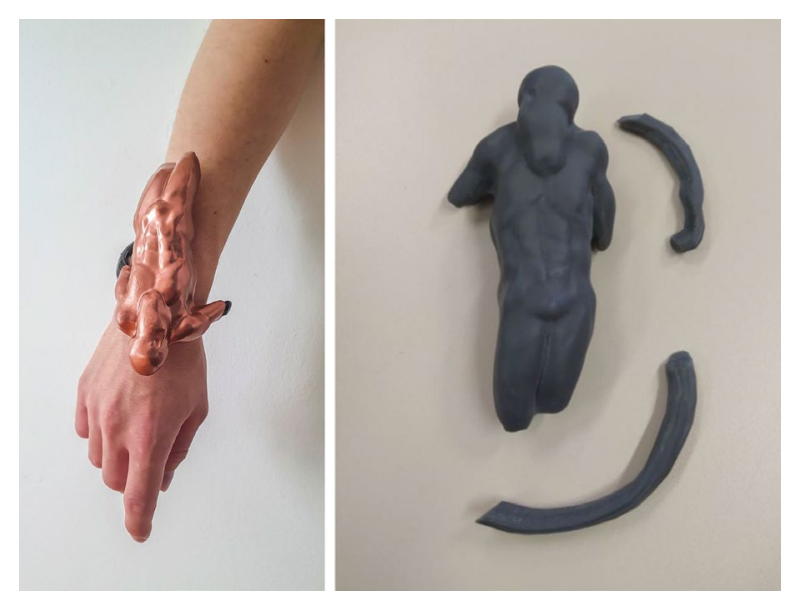

Figure 10: Bracelet from the collection "Tri dobe življenja" (Three Phases of Life), printed with SLA technology on the right and assembled and spray painted on the left, author: Uroš Topić

\subsection{Selective laser melting technology, SLM}

Only a few special pieces of jewellery were selected for printing with metal powder. This technology enables the production of jewellery with final functionality. For this purpose, a $100 \mathrm{~W}$ laser metal printer, LPM100 and a metal powder alloy Co-Cr-Mo -W were used. The layer thickness was adjusted to 100 microns.

After printing with metal powder, the surface of the object is rough to the touch. Therefore, postprocessing is necessary. We used sandblasting and in some cases also polishing. Figures 11, 12 and 13 show the ring, earring and bracelet printed with SLM technology. 

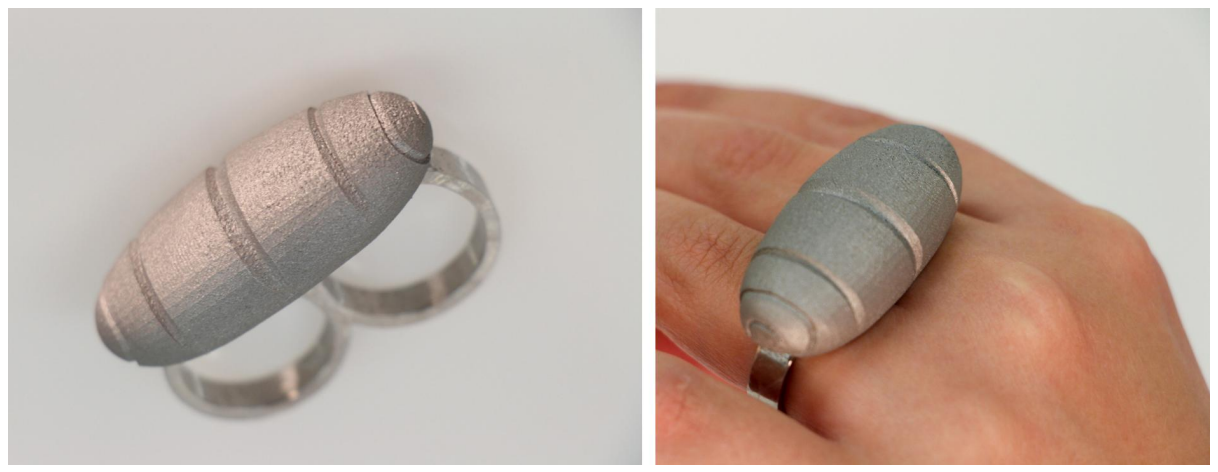

Figure 11: Ring printed with SLM technology, author: Tina Dovjak

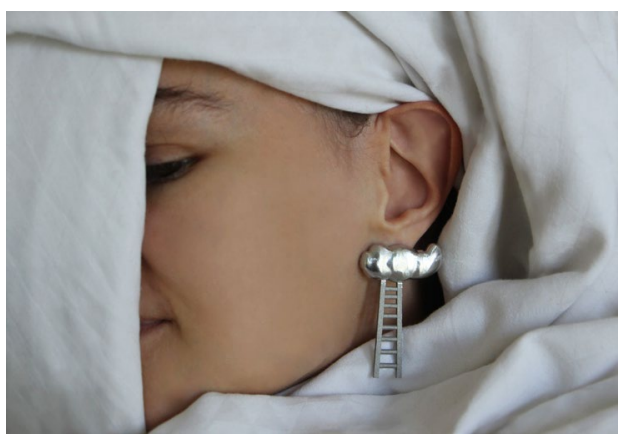

Figure 12: Earring printed with SLM technology, author: Hana Tavčar
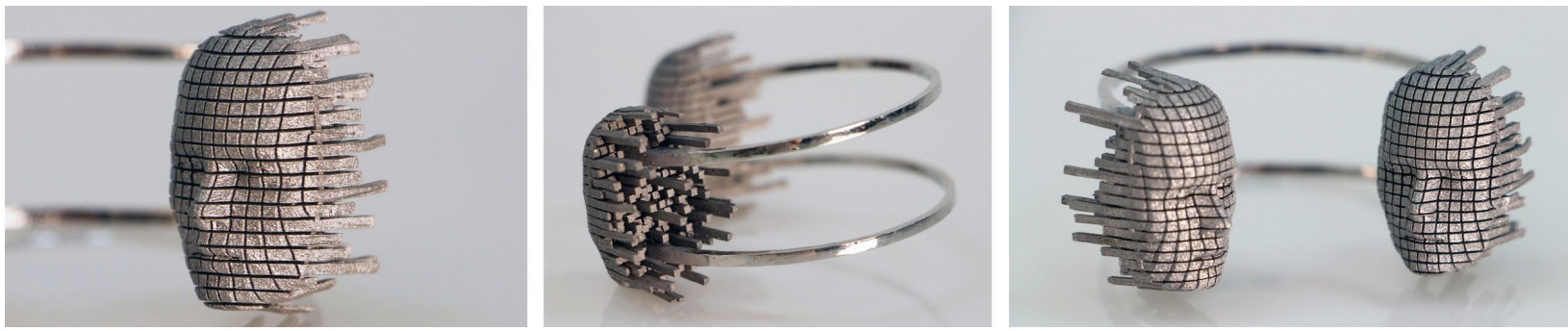

Figure 13: Bracelet from the collection "Dvogovor" (Dialogue) printed with SLM technology, author: Ajda Rep

\section{CONCLUSIONS}

During the course students tested themselves in two new areas that allowed them to expand their design experience, in the field of 3D modeling and in the field of jewellery design. They learned how to interpret a concept and the aesthetics of a piece of a wooden sculpture into a wearable piece of jewellery. They also learned how to transform hand-drawn sketches or images into 3D models. They broaden their knowledge on wooden cultural heritage, jewellery design and various 3D printing technologies.

We have proven that 3D printing technologies are extremely useful for jewellery manufacturing. The production of conceptual and functional prototypes is now possible for almost anyone. The prices of printers that allow printing with thermoplastic materials have already fallen below 300 Euros. However, if we want to print jewellery with full functionality, we have to use technologies that allow printing with metal powder. The prices of metal powder materials for 3D printing have dropped dramatically recently. As a result, printing individual pieces of jewellery is slowly becoming available to every user.

\section{ACKNOWLEDGEMENT}

The presented research is part of the International project Erasmus + Re / Forma Viva Reformation of education on wood preservation. The implementation of the project is funded by the European Commission and takes place under the auspices of the national agency CMEPIUS. 


\section{REFERENCES}

[1] Anderson, C.: "Makers: The New Industrial Revolution”, (Crown Business, USA, 2013.), pages 17-32.

[2] Ferreira, T., Almeida, H.-A., Bártolo, P.-J., Campbell, I.: "Additive Manufacturing in Jewellery Design", Proceedings of Engineering System Design and Analysis 2012, (ASME: Nantes, France, 2012), pages 187-194.

[3] FormLabs, Using Grey Pro Resin, URL: https://support.formlabs.com/s/article/Using-Grey-Pro-Resin?language=en_US (last request: 2020-09-25.).

[4] Milovanović, G., Rožman, H.: "Forma Viva", URL: https://www.galerija-bj.si/forma-viva (last request: 2020-09-27.).

[5] Yap, Y. L., Yeong, W. Y.: "Additive manufacture of fashion and jewellery products: a mini review", Virtual and Physical Prototyping 9, 195-201, 2014. doi: 10.1080/17452759.2014.938993.

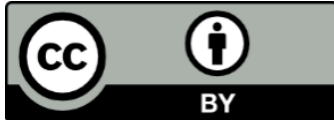

(C) 2020 Authors. Published by the University of Novi Sad, Faculty of Technical Sciences, Department of Graphic Engineering and Design. This article is an open access article distributed under the terms and conditions of the Creative Commons Attribution license 3.0 Serbia (http://creativecommons.org/licenses/by/3.0/rs/). 